\title{
Is tobacco use a disease?
}

\section{Katherine Frohlich PhD}

$\mathrm{S}$ hould tobacco use be framed as a disease or a population-based health concern?' At present, there are 2 potentially competing approaches to reducing smoking rates. The first, the disease-centred approach, identifies smoking as an individual-level disorder requiring medical treatment. The second, the population approach, views smoking as a collective behaviour, one shaped by social norms and attitudes and amenable to change through population-level interventions. I will explore some of the ramifications of framing tobacco use as a disease or a population-based behaviour.

\section{Smoking and the disease-centred approach}

The disease-centred approach to viewing smoking was officially acknowledged by the American Psychiatric Association in 1980 (Box 1). That year, the association included tobacco dependence as a psychiatric diagnosis in its third edition of the Diagnostic and Statistical Manual of Mental Disorders (DSM-III). ${ }^{6}$ Following this bold move, the US surgeon general, in his 1988 report, declared cigarette smoking to be an addiction. ${ }^{7} \mathrm{He}$ further asserted that the pharmacologic and behavioural processes that determine tobacco addiction are similar to those for drugs such as heroin and cocaine. Since then, many practitioners have viewed cigarette smoking as a disease requiring medical attention.

Once smoking was labelled as a disease, research adopting this perspective intensified. As a result, researchers explored individual-level interventions such as therapeutic drug targets. Forms of treatment have ranged from nicotine replacement therapy such as the patch, gum and nasal sprays, other medications and even vaccines. Indeed, in 2000, an article in NIDA Notes from the US National Institute on Drug Abuse announced that "some form of vaccination against nicotine would be highly useful because vaccinated individuals would not get a 'kick' from the nicotine in tobacco smoke or chewing tobacco." ${ }^{\prime \prime}$ These forms of treatment are all based on the premise that smoking is addictive and characterized by compulsive drug seeking. ${ }^{9}$

Although a disease-centred approach may be cost-efficient when appropriately applied and tailored to the needs of individual smokers, it has 2 important shortcomings. First, it is solely curative, focusing largely on helping individuals quit rather than preventing uptake. Second, it addresses smoking at only an individual level and misses the collective and social nature of this health epidemic.

\section{Smoking and the population approach}

In response to the shortcomings of the disease-centred approach to smoking cessation and prevention, public health developed a population approach in the 1980s. This approach is

\section{Key points}

- There are currently 2 approaches to reducing smoking rates: a disease-centred approach and a population approach.

- The disease-centred approach focuses on curative solutions to quit smoking at the individual level.

- The population approach reduces the population prevalence of smoking by altering societal norms.

- An unexpected consequence of population-based interventions is a widening of social inequalities in smoking.

- New strategies to reduce smoking rates should involve not only the health care sector but other sectors such as education and employment.

- Members of vulnerable populations should be involved in the design and evaluation of strategies for smoking prevention and cessation.

based largely on the ground-breaking work of Geoffrey Rose, ${ }^{10,11}$ a British physician and public health leader. Rose's population approach is based on a number of premises, one of which is of particular importance to tobacco control. He postulated that the distribution of risk exposure in a population is shaped by contextual conditions (e.g., the imposition of smoke-free laws in public places). ${ }^{10}$

To illustrate this premise, Rose demonstrated that the causes of individual cases are distinct from the causes of incidence. As an example of the phenomenon, Cronin ${ }^{12}$ demonstrated that the distribution curve of homicides per million per year across the lifespan of males is the same between England/Wales and Chicago. However, the incidence is 30fold higher in Chicago. So, although the causes of individual cases might be the same for the 2 areas, the determinants of the incidence rates may be quite different.

Rose's theory has important implications for the prevention and reduction of smoking in populations. According to Rose's model, the determinants of individual smoking are different from the determinants of population smoking. Important differences in the causes of smoking between populations and individuals will invariably lead to different intervention approaches to smoking prevention and cessation, largely depending on whether one places the emphasis on decreasing incidence or individual cases.

Unlike the individual disease-centred forms of intervention, population-based interventions involve mass environmental programs and policies that attempt to alter society's norms of behaviour. ${ }^{10}$ The usual strategy of population-based tobacco reduction programs is to render tobacco use abnormal, less acceptable, less desirable and less common as a pub-

Katherine Frohlich is with the Department of Social and Preventive Medicine, University of Montréal, Montréal, Que. 
lic or social behaviour. By changing attitudes toward smoking in society, the number of people who attempt to quit, as well as the number of quit attempts per person, increases. ${ }^{13}$

Current examples of this strategy include public banning and increases in cigarette taxes. Indeed, there is a growing body of empirical research demonstrating that population approaches to tobacco control have been effective in reducing prevalence and incidence of smoking. In a systematic review of the literature on the effects of smoke-free workplaces on smoking behaviour among employees, Fichtenberg and Glant $^{14}$ found that the implementation of total bans on smoking in the workplace was associated with a reduction in absolute prevalence of $3.8 \%$ and a decrease in consumption of 3.1 cigarettes per day. In another comprehensive review of interventions seeking to reduce tobacco use, Hopkins and colleagues ${ }^{13}$ found that 8 of 9 studies measuring self-reported cigarette consumption as a consequence of smoking bans reported a median absolute reduction of 1.2 cigarettes per day with a follow-up of 2 years.

The population approach has been immensely successful in Canada. Based on the federal government's adoption of a comprehensive tobacco control policy in 1986, this approach has involved the implementation of a series of strategies. Components of this approach include policy development, legislation and regulations, enforcement, mass media campaigns, community action, public education and taxation. ${ }^{15} \mathrm{In}-$ deed, recent data from the Canadian Tobacco Use Monitoring Survey ${ }^{16}$ shows estimates of the population prevalence of daily smoking among Canadians aged 15 years and older at $19 \%$, down from $50 \%$ in $1965 .{ }^{17}$

In Canada the population approach to smoking cessation and prevention is facing 2 important shortcomings. First, the population prevalence of smoking has stagnated at about $19 \%$ for the last 3-4 years. There is rising concern within the tobacco control community that the "low hanging fruit have been picked" and that the population approach may no longer be effective in bringing rates down further.

Second, smoking prevalence is beginning to exhibit an increasingly steep social class gradient. ${ }^{18,19}$ For all age groups, people in lower socio-economic groups are experiencing slower rates of decline in smoking than those in higher socioeconomic groups. ${ }^{20}$ It has begun to be argued that population-

Box 1: Major milestones in the history of smoking

- Turn of the 20th century: Smoking is deemed to be safe when done in moderation by men ${ }^{2}$

- 1948: The Framingham Heart Study, a community-based cohort study, establishes the link between individual smoking and the development of cardiovascular disease ${ }^{3}$

- 1964: The report of the US surgeon general announces a causal link between cigarette smoking and lung cancer ${ }^{4}$

- 1974: The Lalonde report defines smoking as an individual risk behaviour ${ }^{5}$

- 1980: The American Psychiatric Association includes tobacco dependence in its third edition of the Diagnostic and Statistical Manual of Mental Disorders $\left(\right.$ DSM-III) ${ }^{6}$ based interventions themselves may be contributing to the unintended exacerbation of social inequalities in health and behavioural outcomes such as smoking. ${ }^{21}$

Empirical observation suggests that people with the most financial and educational resources adapt more quickly and easily to population-based interventions. ${ }^{22}$ Population approaches to smoking cessation and prevention may thus be unable to address differential abilities to respond to these interventions. As such, population approaches may be unintentially contributing to increases in social inequalities in smoking.

The last 30 years have seen the tobacco control community focus on 2 complementary ways of reducing smoking rates: the disease-centred approach and the population approach. The failure to reduce smoking prevalence further in recent years, however, should not serve as a validation of the diseasecentred approach to smoking and a corresponding intensification of the search for individual "causes" of smoking. Similarly, more benefit should not be expected from the use of population-based interventions alone.

Instead, we should consider new approaches to address the needs of the remaining 19\% of the population who are still smoking. We need to better understand why these vulnerable populations, comprised largely but not exclusively of homeless people, Aboriginal people, individuals of lower socio-economic status, adolescents and people with mental illness, have been unable to respond to population-based interventions.

Part of the answer may lie in better understanding the underlying mechanisms that lead to different distributions of risk exposure to smoking among vulnerable populations. These groups, because of their position in society, are commonly exposed to contextual conditions that distinguish them from the rest of the population: conditions that appear to place them at increased risk of both beginning and continuing to smoke. Innovative interventions could therefore focus on what have been termed fundamental causes. ${ }^{21}$ These causes, such as low socio-economic status or low levels of education, are the risks that generate exposure to other risks (e.g., smoking).

A tentative suggestion for new intervention strategies that would both complement the disease-centred and population approaches and address the particular needs of these vulnerable populations would include 2 components: the strategies should be "intersectoral" and "participatory." They should be intersectoral because fundamental causes lie largely outside of the health care sector. In the case of smoking, the health care sector may thus need to engage with other sectors, such as employment or education, to reduce disparities associated with smoking. The strategies should be participatory because there are some incongruencies between population approaches and vulnerable populations' needs with respect to smoking. As such, vulnerable populations need to be included in the articulation of intervention development and its evaluation.

This article has been peer reviewed.

Competing interests: None declared. 


\section{REFERENCES}

1. Advancing tobacco control in Canada: learnings from World Cafée. Ottawa (ON): Canadian Council for Tobacco Control; 2008.

2. Rudy J. The freedom to smoke: tobacco consumption and identity. Montreal (QC): McGill-Queen's University Press; 2005.

3. Dawber TR, Meadors GF, Moore FEJ. Epidemiological approaches to heart disease: the Framingham Study. Am J Public Health 1951;41:279-86.

4. US Department of Health, Education and Welfare (1964). Smoking and health: report of the Advisory Committee to the Surgeon General of the Public Health Service. Washington (DC): The Department; 1964. Available: http://profiles.nlm.nih .gov/NN/B/B/M/Q/_nnbbmq.pdf (accessed 2008 Sept 24).

5. Lalonde M. A new perspective on the health of Canadians. Ottawa (ON): Government of Canada; 1974. Available: www.hc-sc.gc.ca/hcs-sss/alt_formats/hpb-dgps /pdf/pubs/1974-lalonde/lalonde_e.pdf (accessed 2007 Oct 22).

6. Diagnostic and statistical manual of mental disorders. Arlington (VA): American Psychiatric Association; 1977.

7. The health consequences of smoking: nicotine addiction. A report of the surgeon general. Rockville (MD): US Department of Health and Human Services; 1988. Available: http://profiles.nlm.nih.gov/NN/B/B/Z/D/_/nnbbzd.pdf (accessed 2008 Apr 3).

8. Shine B. Nicotine vaccine moves toward clinical trials. NIDA Notes 2000;15(5). Available: www.drugabuse.gov/NIDA_Notes/NNVol15N5/Index.html (accessed 2008 Apr 3).

9. Leshner AI. Addiction research can provide scientific solutions to the problem of cigarette smoking. NIDA Notes 1998;13(3). Available: www.drugabuse.gov/NIDA Notes/NNVol13N3/DirRepVol13N3.html (accessed 2008 Apr 3).

10. Rose G. Sick individuals and sick populations. Int J Epidemiol 1985;14:32-8.

11. Rose G. The strategy of preventive medicine. Oxford (UK): Oxford University Press; 1992.

12. Cronin H. The ant and the peacock: altruism and sexual selection from Darwin to today. New York (NY): Cambridge University Press; 1991.

13. Hopkins DP, Briss PA, Richard CJ, et al. Reviews of evidence regarding interventions to reduce tobacco use and exposure to environmental tobacco smoke. Am J Prev Med 2001;20:16-66.

14. Fichtenberg CM, Glantz SA. Effect of smoke-free workplaces on smoking behaviour: systematic review. BMJ 2002;325:188.

15. World Health Organization (WHO) Tobacco Free Initiative and WHO Study Group on Tobacco Product Regulation. Best practices in tobacco control: regulation of tobacco products, Canada report. Geneva (Switzerland): The Organization; 2005.

16. Canadian Tobacco Use Monitoring Survey (CTUMS). Ottawa (ON): Health Canada; 2007. Available: www.hc-sc.gc.ca/hl-vs/tobac-tabac/research-recherche /stat/index_e.html (accessed 2008 Apr 3).

17. Health Canada. The national strategy: moving gorward - the 2006 progress report on tobacco control. Ottawa (ON): Health Canada; 2006. Available: www.hc-sc.gc .ca/hl-vs/pubs/tobac-tabac/prtc-relct-2006/part2_e.html (accessed 2008 Aug 21).

18. Barbeau EM, Krieger N, Soobader MJ, et al. Working class matters: socioeconomic disadvantage, race/ethnicity, gender, and smoking in NHIS 2000. Am J Public Health 2004:94:269-78.

19. Health Canada. The national strategy: moving gorward - the 2005 progress report on tobacco control. Ottawa (ON): Health Canada; 2005. Available: www.hc-sc.gc .ca/hl-vs/pubs/tobac-tabac/foward-avant/index-eng.php (accessed 2008 Aug 21)

20. Harman J, Graham H, Francis B, et al. Socioeconomic gradients in smoking among young women: a British survey. Soc Sci Med 2006;63:2791-800.

21. Frohlich KL, Potvin L. The inequality paradox. The population approach and vulnerable populations. Am J Public Health 2008;98:216-21.

22. Phelan J, Link B. Controlling disease and creating disparities: a fundamental cause perspective. J Gerontol B Psychol Sci 2006;60(suppl):27-33.

Correspondence to: Dr. Katherine Frohlich, Department of Social and Preventive Medicine, University of Montréal, 1430 Blvd. Mont Royal, Montréal QC H2V 4P3; fax 514 343-5645;

katherine.frohlich@umontreal.ca 